Arroyo, P., Christensen, R. Schöttle, A. \& Long, D. (2019). "Lessons Learned on Teaching Choosing by Advantages" In: Proc. 27th Annual Conference of the International. Group for Lean Construction (IGLC), Pasquire C. and Hamzeh F.R. (ed.), Dublin, Ireland, pp. 405-416. DOI: https://doi.org/10.24928/2019/0249. Available at: <www.iglc.net>.

\title{
LESSONS LEARNED ON TEACHING CHOOSING BY ADVANTAGES
}

\author{
Paz Arroyo $^{1}$, Randi Christensen ${ }^{2}$, Annett Schöttle ${ }^{3}$, and David Long ${ }^{4}$
}

\begin{abstract}
Decision-makers on construction projects are faced with complex, multidimensional challenges that require grounded, thoughtful decisions be made to further the project. This paper discusses a breadth of strategies for training construction teams to implement the Choosing By Advantages (CBA) decision-making method. These strategies are analyzed based on coaches' experiences and observations in terms of short and long-term learning outcomes. The unique circumstances of every construction project requires that lean coaches draw from a variety of teaching techniques to tailor the learning process to the specific needs of trainees. For example, while some trainees can quickly learn the basics of CBA theory, they often struggle to implement CBA in a practical context if not provided with proper support. Coaching proves efficacious in enabling construction teams to both make and carry-out decisions, however, a long period of training (12-16 weeks) is often necessary for thorough implementation and expertise in CBA.
\end{abstract}

\section{KEYWORDS}

Learning, Teaching, Choosing by Advantages, Decision-Making.

\section{INTRODUCTION}

CBA is a decision-making system developed by Jim Suhr that is based on four principles: (1) Decision-makers must learn and skillfully use sound methods, (2) Decisions must be based on the importance of advantages, (3) Decisions must be anchored to relevant facts, and (4) Different decisions call for different methods. This paper will focus on the first principle (Suhr 1999). CBA has gained more attention in the construction industry in recent years. This increase has been driven by demands for more collaborative project organizations and transparent decision-making processes; by the synergy of CBA with other agendas such as improving sustainability and safety; and by an increasing need to

1 DPR Quality Leader, San Francisco, CA, PazA@dpr.com, and Founder and Co-Director, CollabDecisions, www.collabdecisions.com.

2 Lean Manager, Lower Thames Crossing, COWI, UK, RMCH@ cowi.com and Founder and Co-Director, CollabDecisions, www.collabdecisions.com.

3 Senior Consultant, Refine Projects AG, Stuttgart, Germany, annett.schoettle@refineprojects.com and Founder and Co-Director, CollabDecisions, www.collabdecisions.com.

4 Regional Lean Manager, Turner Construction Company, Oakland, CA., dalong@ @tcco.com. 
incorporate multiple factors into the decision-making process. However, as the construction industry simultaneously prioritizes delivery logics confined by tight schedules and budgets there is a competing desire to maximize efficiency and timeliness in training processes. Decision-makers seek training protocols with minimal disruption of delivery, even at the expense of quality in education. It is therefore crucial for decision-makers and coaches to think critically about how to provide the most effective training based on the financial resources of the project. This paper compares the experiences of four CBA coaches working separately in different countries and analyzes the skill development of the teams based on the methods of training they received. The primary research question is: What are the benefits and shortcomings of each of the CBA training methods employed by the coaches studied in this paper? This will be evaluated by comparing different styles of training with the learner's subsequent ability to implement CBA. First, this paper will present relevant literature on human learning to contextualize the need for a range of training options. The research methods used to observe more than 30 CBA trainings will be explained and the accompanying data presented. Finally, the outcomes will be discussed, and conclusions drawn regarding how this research can facilitate other coaches and decision-makers in the industry in personalizing CBA trainings to every unique audience.

\section{LITERATURE REVIEW ON LEARNING}

\section{LEARNING NEW PRACTICES}

Each individual begins the learning process from their own context of prior knowledge and experience (Nonaka and Takeuchi 1995). Through this lens individuals negotiate new situations in relation to pre-formed expectations that serve as a filter for incoming mental stimuli, and thus deviations from expected occurrences garner more mental attention than do normative situations (Nørretranders 1991). Daniel Kahneman distinguishes between System 1 and System 2 mental processing to further elucidate how individuals process information; System 1 operates based on intuition and instinct, while System 2 allocates mental attention to occurrences and activities that are unusual or require complex computational thinking (Kahneman 2011). Simultaneously, according to the pragmatist John Dewey, when a situation does not comply with an individual's expectation their perception of the world is challenged (Elkjær 2000). The resulting conflict between the situation and expectation creates the potential for learning through critical reflection and increases the ability to respond to similar situations in the future (Christensen 2008). The integral role of expectations as the context for learning means that it is essential for teachers to consider what knowledge, experiences, and habits learners have already integrated in their perception of the world. However, even while the tension between expectation and reality opens new avenues for mental growth, Brown and Duguid (1991) point to the problem that "most learning theory, including that implicit in most training courses, tends to endorse the valuation of abstract knowledge over actual practice and as a result to separate learning from working and more significantly, learners from workers" (p. 41). The disconnect between theory and practice is a barrier for learners' ability to apply newly acquired knowledge either in a practical setting or even in more complex thought scenarios 
requiring analysis on the level of System 2 thinking (Kahneman 2011; Münster 2017). Thus, it is not only the individual perspective of the learner which is important, but also the approach of the coach, which impacts the ability of learners to apply the acquired knowledge or skills to a work situation. Moreover, learning is influenced by mood. Negative moods (e.g., confusion, resignation, frustration, arrogance, impatience, etc.), inhibit learning until they can be identified and navigated through. Other moods such as curiosity, patience, trust, wonder, confidence, and ambition can facilitate learning (Flores 2016). Sensitivity to the effects of mood in either disrupting or supporting the learning process suggests that learning itself is a skill defined by the ability to cultivate optimal learning environments and attitudes.

\section{Stages of LEARNING AND EFFECTIVE WAYS OF TRAINING}

Stuart and Hubert Dreyfus (1980) present a model of the mental activity involved in skill acquisition. They describe the stages from beginner, advanced beginner, competent, proficient, expert and master (see Table 1). After observing the learning processes of several professions, Dreyfus (1980) concludes that for an individual to successfully acquire new skills they must be willing to take risks, make mistakes, and be emotionally engaged. Practically speaking, this means accepting the joy of successes and accomplishments as much as remorse over breakdowns and failures. Successful teachers and students are actively engaged in creating a mood that is conducive to learning. Different training settings will be more appropriate than others for the specific needs of the learners and requirements of the project - for example, a classroom approach will have a different impact on skill acquisition and development than a learning-by-doing approach.

Table 1: Dreyfus stages of learning.

\begin{tabular}{cc}
\hline $\begin{array}{c}\text { Beginner } \\
\text { Advance Beginner } \\
\text { Competent }\end{array}$ & $\begin{array}{c}\text { Follow rules, do not see context. } \\
\text { Task oriented, begins to recognize different situations. } \\
\text { Exoficient }\end{array}$ \\
$\begin{array}{c}\text { Expert } \\
\text { Master }\end{array}$ & $\begin{array}{c}\text { Developed intuitions on what needs to be done. } \\
\text { principles. }\end{array}$ \\
Intuition well developed. known how to act on different contexts. \\
Subconscious Expertise. Can generate knowledge from anomalies.
\end{tabular}

\section{RESEARCH METHOD AND DATA COLLECTION}

This paper uses Design Science Research (DSR) to evaluate evidence of learning and gain knowledge to inform best practices (Van Aken 2004). Different CBA training methods were studied to understand the effects of each and to determine the circumstances for which each alternative is best suited. The following three criteria were defined for the purpose of the analysis:

- Ability of the team to make a CBA decision with an external facilitator

- Ability of the team to make a CBA decision without an external facilitator 
- Ability of the team to teach CBA to other members who did not participate in the training

For the purpose of the study "ability" refers to the participants adherence to CBA principles, use of CBA language, and resistance to digressions back to previous practices. The study acknowledges that learning CBA is not a straightforward process, nor can it typically be completed in the course of a single training session. In describing the outcomes of each type of training the study refers to the Dreyfus stages of learning to evaluate skills acquired. These evaluations are based on the coaches' observations; feedback received during the training in the form of evaluations, comments, and questions; and subsequent conversations with participants, including requests for more support in applying CBA. During some of the trainings analyzed, coaches were able to directly observe participants applying CBA on projects and therefore judge the practical ability of the participants as a result of training. Recognizing the risk that coaches are biased towards the quality of their own performance, group critique and retrospective feedback sessions were regularly held to assess performance. The specific process of gathering evidence and data is further described for each training below. Table 2 identifies the seven training alternatives evaluated (A-H) as well as the number of trainings facilitated by each coach (C1 to $\mathrm{C} 4)$.

\section{TRAINING ALTERNATIVES AND EVALUATIONS}

The following trainings were designed and implemented to coach construction industry practitioners in employing CBA. This section describes each alternative in detail.

\section{Alternative A - CoAChing ONE DeCision}

Often coaches are hired to help projects grapple with a single critical decision. For example, assistance was sought in choosing a ceiling material for a commercial building (see Arroyo et al. 2015) and in choosing a project architect and general contractor for a capital project. In these cases, coaches briefly presented CBA to decision-makers (30 to 60 minutes) and discussed how it might be implemented in the specific context of the project. Due to time constraints the presentation did not include practical examples or a systematic introduction to CBA. Further coaching and support were sometimes available after the presentation. The provided support varied from 4-40 hours of coaching depending on the initial basis of understanding with regard to the factors, criteria, and attributes of the decision with which the decision-makers began; the complexity of the decision in question; and the amount of data that stakeholders had gathered prior to training. In several cases decisions were delayed because more data was required or because new stakeholders had to be included in the decision-making process. The process was also fraught as practitioners unfamiliar with CBA were asked to diverge from habitual methods; several times participants proposed weighting a variety of factors rather than identifying advantages, or tried to include cost as a factor rather than a constraint, both of which are antithetical to the CBA method. 
Table 2: Overview of training alternatives

\begin{tabular}{|c|c|c|c|c|c|}
\hline & Training alternatives & C1 & C2 & C3 & C4 \\
\hline A & $\begin{array}{l}\text { - } 30 \text { to } 60 \text { minutes explanation of CBA and then facilitate a team } \\
\text { decision supported by a coach (from } 1 \text { to } 5 \text { days). } \\
\text { - Internally for a project, including different stakeholders. }\end{array}$ & 4 & 1 & 0 & 2 \\
\hline B & $\begin{array}{l}\text { - } 30 \text { to } 60 \text { minutes explanation of CBA and then facilitate a series of } \\
\text { team decision supported by a coach for } 10-12 \text { weeks. } \\
\text { - Internally for a project. }\end{array}$ & 2 & 0 & 0 & 1 \\
\hline C & $\begin{array}{l}\text { - Remote training } 2 \text { hours per week for } 12 \text { weeks, in addition to coach } \\
\text { support for several decisions. } \\
\text { - Internally for a project. }\end{array}$ & 1 & 0 & 0 & 0 \\
\hline D & $\begin{array}{l}\text { - Face to face training } 2 \text { hour per week for } 10 \text { weeks (1-hour training } \\
\text { and } 1 \text {-hour coaching on practical examples form the project), plus } \\
\text { minimum } 2 \text { CBA decisions with trained facilitator as coach. } \\
\text { - Internally for a project. }\end{array}$ & 0 & 1 & 0 & 0 \\
\hline E & $\begin{array}{l}\text { - 1-day CBA workshop. } \\
\text { - Mixed project teams and companies. Usually sponsored by an } \\
\text { organization or universities. }\end{array}$ & 5 & 0 & 0 & 3 \\
\hline $\mathbf{F}$ & $\begin{array}{l}\text { - 2-day CBA workshop. } \\
\text { - Mixed project teams and companies. }\end{array}$ & 1 & 0 & 0 & 0 \\
\hline G & $\begin{array}{l}\text { - } 1 / 2 \text { day CBA workshop with practical training on user examples } \\
\text { - Same company, different countries, departments and magmt. levels. }\end{array}$ & 0 & 0 & 13 & 0 \\
\hline H & $\begin{array}{l}\text { - 1-day training as part of a CBA train the trainer certification process. } \\
\text { - Same company, different countries, departments and mgmt. levels. }\end{array}$ & 0 & 0 & 1 & 0 \\
\hline
\end{tabular}

Alternative B - COACHING SEVERAL DECISIONS

Coaches also respond to requests to help projects with several decisions, such as choosing the interior design, MEP design, and landscape design of a capital project for an IT company in the U.S. (Arroyo and Long 2018); or choosing the location, layout, structural system materials, and schematic design of a commercial building in Chile. In these cases, in addition to a brief CBA introduction (as in Alternative A), coaches had the opportunity to introduce CBA in different practical contexts and participants gained more exposure to the method by making decisions together. After making several decisions (4-20) using CBA practitioners had both learned the theory and had the chance to integrate that knowledge, leading to a greater understanding of why CBA focuses specifically on the importance of advantages involved in decisions. Practitioners began to take initiative in the decision-making process by, for example, identifying alternatives without being prompted by the coach, investigating factors and criterion, and coming to meetings with pre-prepared lists of attributes. In most cases, by the end of the third to sixth decision made with the CBA coach, practitioners had developed skills that would qualify them as "advanced beginners" to "competent".

\section{Alternative C - Formal Training}

In some cases, companies seek formal training for their employees or project participants. In one instance, the hired coach developed a training program for 10 team members, working for a U.K. highway tunnel project (Highway England) to be educated in 
facilitating CBA; 12 weekly 2-Hour sessions were conducted remotely. This extended training format allowed for in-depth study of CBA concepts, vocabulary, principles, and methods. Participants read relevant literature on the topic and completed learning exercises and homework tasks. The structure allowed participants to think through different application contexts, ask questions, and learn from their peers as well as from their coaches. After completing the training, students' knowledge of CBA varied from "advanced beginner" to "proficient." Several participants applied CBA to personal and work-related decisions and reported their successes back to the coach.

\section{ALTERNATIVE D - FORMAL TRAINING AND COACHING}

After receiving formal training (see Alternative C) the UK highway tunnel project (Highway England) adopted a systematic approach to CBA and adapted CBA tools to the specific needs of the team. This initial adoption of CBA motivated a request for further training, and a coach was hired to teach a second group of 15 project team members. As in Alternative $\mathrm{C}$, the training was a mix of theory, practical exercises, discussions based on real cases from the project, homework, readings, and tests. Trainees also made real project decisions using CBA with support from one or two coaches. According to the coach, after this training participants skills varied from "competent" to "expert" in terms of their ability to support and lead decisions made with CBA. All trainees participated in a community of practice to coordinate, share and further develop their skills. Discussions in this group have revealed that multi-disciplinary training in CBA combining theory, practice and discussion supported a thorough understanding of CBA and the skill to facilitate workshops and apply CBA techniques to other settings.

\section{ALTERNATIVE E - 1 DAY OPEN WORKSHOP}

Conferences and universities have employed CBA coaches to facilitate single-day educational workshops. For example, coaches led presentations at IGLC 2014 in Norway, P2SL-LCI Lean Design Forum 2019 in California, University of Tallinn in Estonia in 2018, and LCI - Canada in 2017 and 2018. The audiences for these trainings represented multiple companies and stakeholders (e.g. owner representatives, architects, engineers, researchers, students) from different backgrounds and project experiences. Workshops aimed to provide an overview of CBA vocabulary, principles, and methods, and included role play exercises to practice skills introduced by the coach. After these workshops, participants' skill level in CBA typically ranged from "beginner" to "advanced beginner." While presentations motivated participants to further their learning or introduce elements of CBA in their work, they often struggled to implement CBA among professionals who were unfamiliar with the concepts and practices. Reliable assessments of the outcomes of these workshops are limited, however, following the workshop at LCI-Canada in 2018 coaches 1 and 4 had the opportunity to meet with participants from the previous year. Only one of these participants was actively using CBA in their organization. Several reported not having implemented CBA, although they expressed intention to do so.

\section{Alternative F - 2 DAYS OPEN WORKSHOP}

In some cases, such as AGC Michigan in 2018, coaches were asked to lead a 2-day CBA workshop. As in Alternative E, participants came from a range of companies and with a 
variety of professional expertise. In addition to the curriculum of a single-day workshop, coaches discussed preference curves, provided more examples of CBA in practice within a variety of contexts, and drew connections between CBA and other lean management principles. Following a two-day workshop practitioners' skill level typically ranged from "beginner" to "advanced beginner", but in the coach's assessment these trainees saw more possibilities for CBA applications than those in Alternative E. After the training at AGC Michigan, a small number of participants requested that coaches support their implementation of CBA in subsequent decisions, demonstrating some level of commitment to applying the skills they acquired during the workshop.

\section{ALTERNATIVE G - 1/2 DAY WORKSHOPS FOR ONE COMPANY}

Coaches have also provided half-day workshops for specific companies. For example, 13 half-day workshops have been conducted as part of a CBA rollout at Daimler AG (see Schöttle et al. 2019). One workshop was facilitated in Mannheim in October 2018, one in Dubai in November 2018, four in Melbourne in December 2018, three in Beijing in January 2019, and four in Bengaluru in February 2019. Participants were beginners who had no prior knowledge of CBA and represented different departments and different management levels. Workshops were individualized to provide practical examples based on participants' needs. Both Two-list and Tabular methods were introduced and explained. CBA tabular exercises were initially to be based on pre-loaded examples by the participants, however the submissions did not contain the required information to develop an example, so pre-existing examples were used. Based on their reflections regarding the practical tabular exercise, participants understood the benefits of using CBA, but also recognized that more training and support would be necessary to implement CBA in their own work. The coach classified participants as "beginners" or "advanced beginners" after engagement in the workshop.

\section{ALTERNATIVE H - "TRAIN THE TRAINER" WORKSHOP FOR ONE COMPANY}

Coaches are also hired to train individuals in CBA facilitation using a "Train the Trainer" curriculum approach. For example, subsequent to the training at Daimler (see Alternative G), a group was identified to participate in a "Train the Trainer" certification program consisting of a 1-day kick-off workshop, a Study Action Group (SAG) reading and facilitation exercise, facilitation of a CBA training session, and coaching of a team to reach an important decision using CBA (see Schöttle et al. 2019). The 1-day kick-off workshop consisted of theory, practical exercises, a test, and guidance about how to facilitate CBA. The first group consisted of 15 participants from different countries, departments, and management levels. Some had previously attended a CBA workshop (see Alternative G), while others had no prior knowledge of CBA. Based on the test result, participants struggled with the precise CBA language, the principles, and the role of money in the CBA method. However, after completing the SAG, participants did have a better understanding of CBA than in Alternative $G$ and after the entire "Train the Trainer" process the participants could be classified as "competent" to "proficient." 


\section{FINDINGS SUMMARY}

Based on observations from separate training situations in several countries, the authors have distilled the main findings regarding the efficacy of a variety of methods for teaching CBA (see Table 3). Table 3 shows the several training and coaching alternatives discussed in this paper, all of which were designed to develop participants' skill in making decisions using CBA principles. All alternatives demonstrated that participants showed potential for decision-making using CBA with the support of a facilitator, however, the level of skill acquisition varied. Skill was best developed when a project team received a combination of formal training and coaching that was grounded in their specific project needs. Workshops provided an opportunity to introduce CBA, begin skill development, and inspire further learning, but participants did not demonstrate significant implementation of CBA in their own work following these trainings.

Table 3: Overview of the findings

\begin{tabular}{|c|c|c|c|}
\hline $\begin{array}{l}\text { Alter- } \\
\text { nativ } \\
\text { e }\end{array}$ & Ability to decide with facilitator & $\begin{array}{l}\text { Ability of the team to make a CBA } \\
\text { decision without external } \\
\text { facilitator }\end{array}$ & $\begin{array}{l}\text { Ability of the team to teach } \\
\text { CBA to other member that } \\
\text { were not part of the training }\end{array}$ \\
\hline A & $\begin{array}{l}\text { Likely, but requires a lot of time to } \\
\text { get the team around to understand } \\
\text { what information they need. }\end{array}$ & $\begin{array}{c}\text { Not likely. Participants tend to go } \\
\text { back to weight factors and attributes } \\
\text { however they have slightly more } \\
\text { awareness on the importance of the } \\
\text { advantages. }\end{array}$ & $\begin{array}{l}\text { Probably a practitioner can } \\
\text { explain a decision, but not } \\
\text { likely to train others. }\end{array}$ \\
\hline B & $\begin{array}{l}\text { Likely, but requires a lot of time to } \\
\text { get the team around to understand } \\
\text { what information they need. Time for } \\
\text { following decisions decreases. }\end{array}$ & $\begin{array}{c}\text { Probably at the end of the course, } \\
\text { they can lead decisions, but depend } \\
\text { on the level of engagement during } \\
\text { coached decisions. }\end{array}$ & $\begin{array}{l}\text { Probably at the end of the } \\
\text { training, some participants } \\
\text { can train new members. }\end{array}$ \\
\hline C & $\begin{array}{l}\text { Very likely, by the end of the training } \\
\text { most practitioners have experienced } \\
\text { a decision made with CBA. }\end{array}$ & $\begin{array}{l}\text { Very probable at the end of the } \\
\text { training, in fact many did. }\end{array}$ & $\begin{array}{l}\text { Probably at the end of the } \\
\text { training, most participants can } \\
\text { train new members. }\end{array}$ \\
\hline D & $\begin{array}{l}\text { Very likely, by the end of the training } \\
\text { all practitioners have experienced } \\
\text { several decisions made with CBA. }\end{array}$ & $\begin{array}{l}\text { Very probable as the training include } \\
\text { them to co-facilitate decisions, and } \\
\text { coach observed them. }\end{array}$ & $\begin{array}{l}\text { Probably at the end of the } \\
\text { training, most participants can } \\
\text { train new members. }\end{array}$ \\
\hline $\mathbf{E}$ & $\begin{array}{l}\text { Uncertain, it is hard to assess } \\
\text { whether a student will be able to } \\
\text { follow CBA principles even with a } \\
\text { facilitator. }\end{array}$ & $\begin{array}{l}\text { Not likely. But some cases have } \\
\text { been documented. }\end{array}$ & $\begin{array}{l}\text { Not likely. But some cases } \\
\text { have been documented. }\end{array}$ \\
\hline $\mathbf{F}$ & $\begin{array}{l}\text { Likely, participants have the chance } \\
\text { make several decisions on the } \\
\text { training, they will be able to apply } \\
\text { CBA with a facilitator. }\end{array}$ & $\begin{array}{c}\text { Not likely, participants do not } \\
\text { necessarily can frame and lead the } \\
\text { decision, especially for weighting } \\
\text { advantages. }\end{array}$ & Not likely. \\
\hline $\mathbf{G}$ & $\begin{array}{l}\text { Likely, by the end of the } 1 / 2 \text { training } \\
\text { participants have experienced a } \\
\text { decision made with CBA in groups } \\
\text { with the help of the facilitator. }\end{array}$ & $\begin{array}{c}\text { Not likely. One person started to use } \\
\text { CBA after the workshop. Others } \\
\text { want to and will participate in a } \\
\text { follow-up to learn more about the } \\
\text { method. }\end{array}$ & $\begin{array}{l}\text { Not at all. More examples and } \\
\text { theoretical background } \\
\text { knowledge necessary. }\end{array}$ \\
\hline $\mathbf{H}$ & $\begin{array}{l}\text { Likely, by the end of the 1-day } \\
\text { training participants have } \\
\text { experienced a decision made with } \\
\text { CBA in groups with the help of the } \\
\text { facilitator and have the chance of } \\
\text { solve question in the SAG. }\end{array}$ & Not likely. & $\begin{array}{l}\text { Not likely, but a few } \\
\text { participants who attended } \\
\text { several G trainings before } \\
\text { were able. }\end{array}$ \\
\hline
\end{tabular}




\section{DISCUSSION}

In the domain of project delivery, decision logic is accepted to be linear and thus decisionmakers have been rewarded for making decisions quickly, in isolation, and often disconnected from true customer value. Decision-makers used to this logic find it difficult to change their mindset to learn to make decisions collaboratively and based on the importance of advantages rather than by weighting, rating, and calculating, or listing pros and cons. Furthermore, CBA relies on staging the context of the elements of the decision, which is a level of preparation that few are accustomed to. The democratic and collaborative nature of the CBA process equally values the assessments of people at all levels within the organization. In certain organizations this dynamic can appear threatening to upper management, but it is also why CBA is more readily accepted in a lean organization. When applying CBA, practitioners often experience frustration and breakdowns on:

- Vocabulary: Practitioners need time to integrate CBA terminology into their professional vocabulary. Until they become proficient and the vocabulary comes to mind intuitively, it takes a significant effort on the part of the trainee to employ new CBA terms in practice.

- Weighing advantages: Practitioners tend to regress back to weighting factors in decisions and struggle to understand that when using CBA decisions are made based on the importance of advantages. It can be difficult for beginners to understand the importance of advantages, and to weight them.

- Viewing cost as a factor: Beginner practitioners habitually include cost as a factor in decision-making and struggle to trust CBA's approach of separating value from cost. They struggle even further when asked to recognize cost as a constraint.

- Choosing the paramount advantage: It can be difficult for a team to come to consensus when determining the single most important element in decisionmaking. Beginners especially struggle to view matters objectively and consider multiple perspectives. Many get frustrated and defensive; coaches play an essential role in helping them see differently.

- Preference Curve: For a beginner it is confusing to understand the preference curves when scaling the importance of advantages. They tend to struggle with the concept that, within a particular factor, if no alternative offers an advantage then the factor is irrelevant. This is particularly true when quantitative data is involved.

- Argumentation: Many beginners struggle with the use of ethos (appeal to authority or credibility), logos (appeal to logic), and pathos (appeal to emotion) in the argumentation component of CBA (Arroyo et al. 2014). Being more conscious of these strategies, as well as using legal procedure principles, can enable teams to realize a more equitable decision-making process (Koskela et al. 2018).

Decision makers should consider the needs of the project or organization, the desired competence level of the learners, and the context of the learning environment before deciding on the type and extent of the training. Projects that need support in making a 
particular decision might benefit from a short introduction to CBA followed by individualized coaching (Alternative A). Others might need support with several decisions (Alternative $\mathrm{B}$ and $\mathrm{G}$ ), or only want an introduction to the method and its potential before committing to more systematic training and implementation (Alternative C, D, and $\mathrm{H}$ ). Systematic training within the work environment is the most extensive training option and offers the strongest outcomes. Learning is best achieved by integrating CBA in daily practices and routines such that theory is directly anchored to practice. Conducting workshops outside of specific workplace environments (Alternatives E and F) may be effective in providing some inspiration, but is unlikely to lead to significant behavioral or methodological changes. Implementing CBA after an introductory workshop would require considerable self-study and self-discipline, and many attendees who participated alone or as a small group would likely struggle to integrate the knowledge into a larger organization. The findings thereby show a clear connection between experiential learning and the ability to apply the acquired knowledge independently.

\section{CONCLUSIONS}

Short training sessions and coaching a team for a single decision can allow a team to move forward with a particular decision, however this level of education is unlikely to result in the team's ability to utilize CBA without support. Alternatives B, C, D, G, and H, in which coaching, and training is organization-specific, and several practitioners are learning together in a practical environment, offer the best opportunity to develop advanced skills and the ability to implement CBA without a facilitator. In particular, Alternatives D and $\mathrm{H}$, where formal training and coaching is provided over 12-16 weeks, offer the most promising opportunities for developing expertise. A successful training has to facilitate experiential learning, familiarize trainees with CBA language, and address initial resistance to the CBA method.

This research was limited by the imprecision in tracking and measuring the impact of each training alternative, given a lack of opportunities for following up with most training participants. This is particularly true of Alternatives A, E, and F. However, all coaches have received feedback from some participants. Furthermore, the results of this paper could potentially be transferred to other types of lean training e.g. training of The Last Planner System, providing an opportunity for further research.

\section{REFERENCES}

Arroyo, P., Ballard, G., and Tommelein, I. D. (2014). "Choosing by advantages and rhetoric in building design: Relationship and potential synergies." In Proc. 22nd Ann. Conf. of the Int'l Group for Lean Construction, Oslo, Norway, 391-408.

Arroyo, P., Tommelein, I. D., and Ballard, G. (2015). "Selecting globally sustainable materials: a case study using choosing by advantages." Journal of Construction Engineering and Management, 142(2), 05015015.

Arroyo, P., and Long, D. (2018). "Collaborative Design Decisions" In: 26th Ann. Conf. of the Int. Group for Lean Construction, Chennai, India, 463-472 
Brown, J.S, and Duguid, P. (1991). Organizational learning and communities-of-practice: Toward a unified view of working, learning and innovation. Organization Science, 2(1), 40-57.

Christensen, R. (2008). Development Practically Speaking, Learning processes in the Danish Construction Industry. PhD Thesis, Aalborg University.

Dreyfus, S.E., and Dreyfus, H.L. (1980). A five-stage model of the mental activities involved in directed skill acquisition. California Univ. Berkeley Operations Research Center, No. ORC-80-2. Berkeley, CA.

Elkjær, B. (2000). The Continuity of Action and Thinking in Learning: Re-visiting John Dewey. Outlines, Critical Social Studies, 2, 85-101.

Flores, G.P. (2016). Learning to Learn and the Navigation of Moods: The Meta-skill for the Acquisition of Skills. Pluralistic Networks Publishing.

Kahneman, D. (2011). Thinking, Fast and Slow. Penguin Books.

Koskela, L., Arroyo, P., and Ballard, G. (2018). "Designing as a Court of Law." In:, 26th Ann. Conf. of the Int. Group for Lean Construction, Chennai, India, 614-624.

Münster, M. (2017). "Jytte fra Marketing er desværre gået for i dag, Sådan bruger du adfærdsdesign til at skabe forandringer i den virkelige verden (How to use behavioural design to create changes in the real world. In Danish). ISBN 0799702243581, Gyldendal A/S.

Nonaka, I., and Takeuchi, H. (1995). The knowledge creating company. Oxford University Press.

Nørretranders, T. (1991). Mark Verden, En beretning om bevidsthed. Gyldendal.

Schöttle, A., Gigler, L.M., and Mingle, B. (2019). "From concept development to implementation: Choosing by advantages across an organization." In Proc. 27th Annual Conf. of the Int'l Group for Lean Construction, Dublin, Ireland.

Suhr, J. (1999). The choosing by advantages decisionmaking system. Quorum, Westport.

Van Aken, J.E. (2004). "Management Research Based on the Paradigm of the Design Sciences: The Quest for Field-Tested and Grounded Technological Rules." Journal of Management Studies, 41(2), 219-246. 